Article

\title{
The Interactions of Oxygen with Small Gold Clusters on Nitrogen-Doped Graphene
}

\author{
Xin Chen ${ }^{1}$, Shaorui Sun ${ }^{1}$, Fan Li ${ }^{1}$, Xiayan Wang ${ }^{1}$ and Dingguo Xia ${ }^{2, *}$ \\ 1 College of Environmental and Energy Engineering, Beijing University of Technology, \\ Beijing 100124, China \\ 2 College of Engineering, Peking University, Beijing 100871, China \\ * Author to whom correspondence should be addressed; E-Mail: dgxia@pku.edu.cn; \\ Tel.: +86-10-6276-7962; Fax: +86-10-6276-8316.
}

Received: 21 December 2012; in revised form: 1 March 2013 / Accepted: 5 March 2013 / Published: 13 March 2013

\begin{abstract}
By means of density functional theory, the adsorption properties of $\mathrm{O}_{2}$ molecule on both isolated and $\mathrm{N}$-graphene supported gold clusters have been studied. The $\mathrm{N}$-graphene is modeled by a $\mathrm{C}_{65} \mathrm{NH}_{22}$ cluster of finite size. The results indicate that the catalytic activity and the $\mathrm{O}_{2}$ adsorption energies of odd-numbered Au clusters are larger than those of adjacent even-numbered ones. The $\mathrm{O}_{2}$ molecule is in favor of bonding to the bridge sites of odd-numbered $\mathrm{Au}$ clusters, whereas for odd-numbered ones, the end-on adsorption mode is favored. The perpendicular adsorption orientation on $\mathrm{N}$-graphene is preferred than the parallel one for $\mathrm{Au}_{2}, \mathrm{Au}_{3}$ and $\mathrm{Au}_{4}$ clusters, while for $\mathrm{Au}_{5}, \mathrm{Au}_{6}$ and $\mathrm{Au}_{7}$, the parallel ones are favored. When $\mathrm{O}_{2}$ is adsorbed on N-graphene supported Au clusters, the adsorption energies are largely increased compared with those on gas-phase ones. The increased adsorption energies would significantly facilitate the electron transfer from $\mathrm{Au}$ d-orbital to $\pi^{*}$ orbital of $\mathrm{O}_{2}$, which would further weakening the $\mathrm{O}-\mathrm{O}$ bond and therefore enhancing the catalytic activity. The carbon atoms on $\mathrm{N}$-graphene could anchor the clusters, which could make them more difficult to structural distortion, therefore enhance their stability.
\end{abstract}

Keywords: gold cluster; graphene; oxygen adsorption; density functional theory 


\section{Introduction}

As a new kind of catalyst to catalyze $\mathrm{CO}$ oxidation reactions at low temperatures, nanosized gold clusters have recently attracted considerable interest from both the industrial and academic communities due to their unique physical and chemical properties [1-6]. It is well known that gold in its bulk form has little or no catalytic activity. However, small gold clusters exhibit drastically different fundamental properties, which may be exploited in a variety of applications such as catalysis, chemical- and bio-detectors, advanced drug delivery systems, enhanced computing systems and optoelectronics [7]. As one of the key factors to understand the catalytic mechanisms, the adsorption behavior of atomic and molecular oxygen on gold clusters has been studied. It was found that the adsorption behavior of oxygen molecules on a gold cluster strongly depends on the charge status and cluster size [8-10]. Furthermore, an even-odd oscillation behavior of the oxygen adsorption was found in anionic Au clusters. For neutral Au clusters, the systematic studies were deficient, and there is no consistent view on the adsorption behavior of $\mathrm{O}_{2}$. For instance, some studies confirmed there is no adsorption for molecular oxygen on neutral Au clusters [11], but many theoretical studies suggested that the adsorption should happen [12-16].

Very recently the stability or the catalytic properties of Au nanoclusters supported on graphene has attracted much attention. Graphene is a single atomic layer of hexagonal $\mathrm{sp}^{2}$-bonded graphite with unique zero-gap electronic structure and massless Dirac fermion behavior [17-20]. The unusual electronic and structural properties make graphene a good candidate material for the generation of faster and smaller electronic devices. Its current applications in these fields may be extended to the field of heterogeneous catalysis, as support for metal nanoparticles. An enhanced reactivity for methanol oxidation has been recently reported for small platinum clusters and palladium nanoparticles supported on graphene oxide sheets [21-23]. Chen et al.'s calculation indicates that the catalytic properties for $\mathrm{CO}$ oxidation are improved based on $\mathrm{Au}_{16}$ cluster supported on graphene [24]. However, a systematic theoretical study about the interactions of oxygen molecule with Au clusters supported on graphene is lacking.

We report here a density functional theory (DFT)-based investigation of the interactions of oxygen molecule with small Au clusters on a nitrogen-doped graphene surface. We firstly calculated all the possible adsorption conformations of $\mathrm{O}_{2}$ on isolated $\mathrm{Au}_{n}$ clusters $(n=2-10)$, and then the interactions of $\mathrm{O}_{2}$ on $\mathrm{Au}_{n}(n=2-7)$ clusters supported on $\mathrm{N}$-doped graphene (N-graphene) were fully studied. The results obtained indicate that $\mathrm{N}$-graphene is able to stabilize small Au clusters, and enhance their catalytic activity simultaneity.

\section{Methodology}

All the calculations have been performed with the Amsterdam Density Functional (ADF, version 2009.01) program package [25-27], which is based on the DFT of electronic structure. The Perdew-Wang parameterized (PW91) form of the generalized gradient approximation (GGA) for the exchange-correlation functional is adopted in the calculations. The gold atoms were calculated with a triple- $\zeta$ polarized (TZP) slater-type basis set, and other atoms with double- $\zeta$ polarized (DZP) set. The inner core orbitals, $1 \mathrm{~s}$ for $\mathrm{C}, \mathrm{N}$ and $\mathrm{O},(1 \mathrm{~s}-4 \mathrm{f})$ for $\mathrm{Au}$ were kept frozen. Gold being a heavy atom, relativistic effects become important. So the scalar relativistic effects were taken into account in the 
present work. The N-containing graphene $\left(\mathrm{C}_{65} \mathrm{NH}_{22}\right)$ was built which contains pyridine species. Carbon atoms on the edge of the graphene are terminated by hydrogen atoms. For all stationary states, spin multiplicity was allowed to relax: possible geometries with varying spin states were carefully checked and the ground state is determined as the one with the lowest electronic energy. What's more, the atom charges were obtained by Multipole Derived Charge analysis (MDC-q) [28], which gives charges that reproduce by construction both the atomic and molecular multipoles.

The choice of the initial geometry is important to obtain the lowest energy structures. In the current study, we obtained the most stable structures by the following approaches: first, considering previous studies on the configurations of pure Au clusters [29-31], we restudied the structural properties of the neutral $\mathrm{Au}_{n}(n=2-10)$ clusters before investigating the interaction of Au clusters with $\mathrm{O}_{2}$. On the basis of the optimized equilibrium geometries of pure $\mathrm{Au}$ clusters, we obtained the initial structures of $\mathrm{Au}_{n} \mathrm{O}_{2}$ clusters by bonding $\mathrm{O}_{2}$ molecule directly on each possible nonequivalent site of the $\mathrm{Au}_{n}$ clusters. For $\mathrm{Au}_{n}$ clusters supported on $\mathrm{N}$-doped graphene $\left(\mathrm{C}_{65} \mathrm{NH}_{22}\right)$, we firstly relaxed the planar Au clusters for two different orientations (both parallel and perpendicular) relative to the surface, and then made $\mathrm{O}_{2}$ adsorbed on the complexes as explained above. All these initial structures are fully optimized by relaxing the atomic positions until the force acting on each atom is negligible and by minimizing the total energy.

An important reference point for this calculation is the adsorption energy for $\mathrm{O}_{2}$ adsorbed on isolated $\mathrm{Au}_{n}$ clusters, as well as on $\mathrm{N}$-graphene $\left(\mathrm{C}_{65} \mathrm{NH}_{22}\right)$ supported ones. In this paper, we used the following definitions for adsorption energy. When $\mathrm{O}_{2}$ is adsorbed on isolated $\mathrm{Au}_{n}$ clusters, the adsorption energy is calculated as:

$$
E_{1}=E(\text { system })-E\left(\mathrm{Au}_{n} \text { clusters }\right)-E\left(\mathrm{O}_{2}\right)
$$

When $\mathrm{O}_{2}$ is adsorbed on $\mathrm{N}$-graphene supported $\mathrm{Au}_{n}$ clusters, the adsorption energy is calculated as:

$$
E_{2}=E(\text { system })-E\left(\mathrm{Au}_{n} / \mathrm{C}_{65} \mathrm{NH}_{22}\right)-E\left(\mathrm{O}_{2}\right)
$$

Similarly, when $\mathrm{Au}_{n}$ clusters are adsorbed on N-graphene, the adsorption energy is:

$$
E_{3}=E(\text { system })-E\left(\mathrm{C}_{65} \mathrm{NH}_{22}\right)-E\left(\mathrm{Au}_{n} \text { clusters }\right)
$$

\section{Results and Discussion}

\subsection{The Structural and Electronic Properties of Gold Clusters}

In order to obtain the initial geometries of $\mathrm{Au}_{n} \mathrm{O}_{2}$ clusters, we first optimized isolated $\mathrm{Au}_{n}$ clusters and single $\mathrm{O}_{2}$ molecules. The lowest energy geometries and the electronic properties of $\mathrm{Au}_{n}(n=2-10)$ clusters shown in Figure 1 are in good agreement with previous works [31-35]. The spin multiplicity, average $\mathrm{Au}-\mathrm{Au}$ bond length, binding energy per atom, and the energy gap between the highest occupied molecular orbital (HOMO) and lowest unoccupied molecular orbital (LUMO) are listed in Table 1. The average $\mathrm{Au}-\mathrm{Au}$ bond length and binding energy per atom increase monotonically as a function of the size of the cluster. The values of HOMO-LUMO energy gap clearly indicate an even-odd oscillation behavior in $\mathrm{Au}_{n}$ clusters, that is, the even-numbered clusters have higher HOMO-LUMO gap than the odd-numbered neighbors. 
Figure 1. Optimized geometries for pure $\mathrm{Au}_{n}(n=2-10)$ clusters, single $\mathrm{O}_{2}$ molecule and $\mathrm{Au}_{n} \mathrm{O}_{2}(n=2-10)$ complexes (distances are in angstrom).

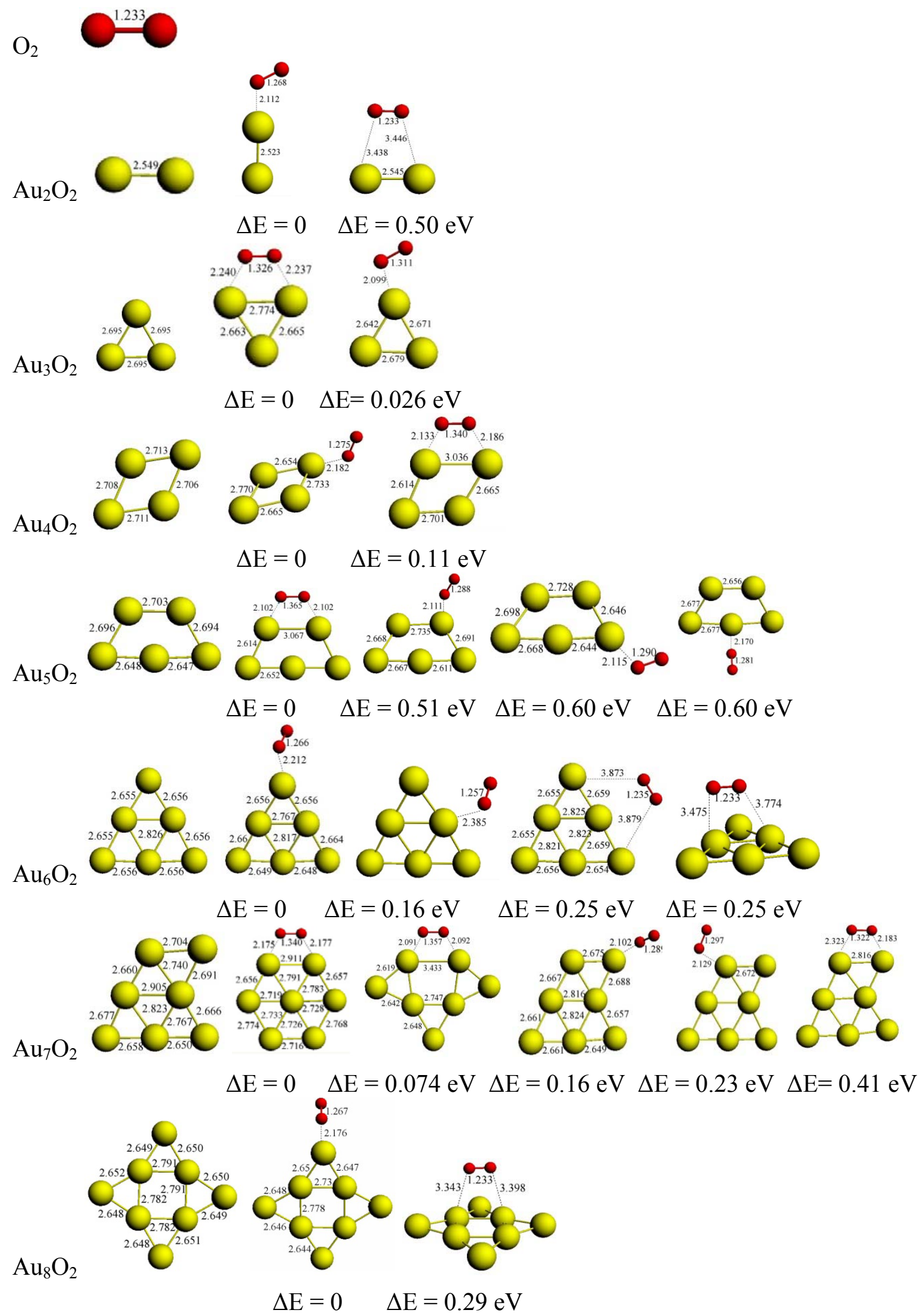


Figure 1. Cont.
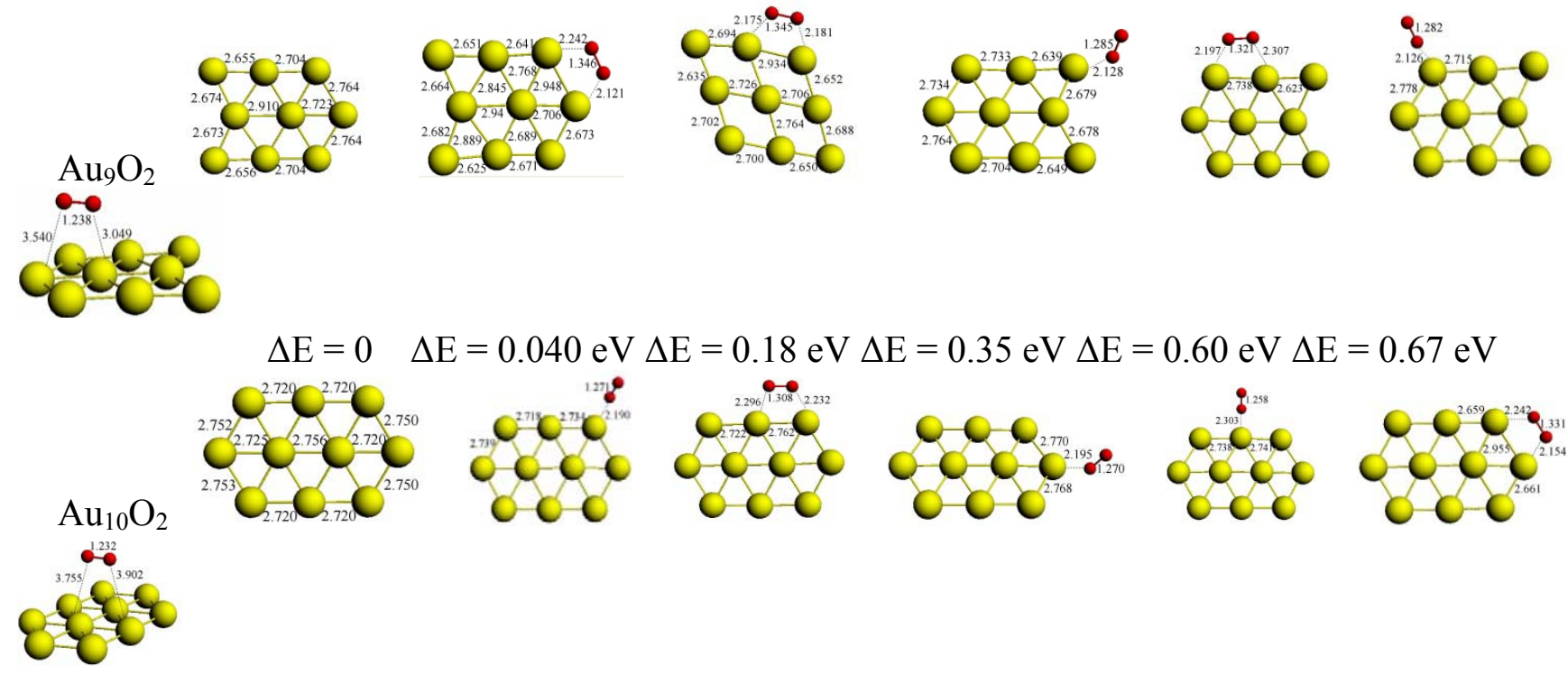

$$
\Delta \mathrm{E}=0 \mathrm{eV} \Delta \mathrm{E}=0.0048 \mathrm{eV} \Delta \mathrm{E}=0.013 \mathrm{eV} \Delta \mathrm{E}=0.14 \mathrm{eV} \Delta \mathrm{E}=0.19 \mathrm{eV} \Delta \mathrm{E}=0.29 \mathrm{eV}
$$

Table 1. Calculated structural parameters of $\mathrm{Au}_{n}(n=2-10)$ clusters. The values in the parentheses are taken from other works.

\begin{tabular}{|c|c|c|c|c|}
\hline $\begin{array}{c}\mathrm{Au}_{n} \\
\text { cluster }\end{array}$ & $\begin{array}{c}\text { Spin } \\
\text { multiplicity }\end{array}$ & $\begin{array}{c}\text { Average bond } \\
\text { length }(\AA)\end{array}$ & $\begin{array}{l}\text { Binding energy } \\
\text { per atom }(\mathrm{eV})\end{array}$ & $\begin{array}{l}\text { HOMO-LUMO } \\
\text { energy gap }(\mathrm{eV})\end{array}$ \\
\hline $\mathrm{Au}_{2}$ & 1 & $2.549(2.53,2.47)^{\mathrm{a}, \mathrm{b}}$ & 1.12 & $2.01(1.96)^{\mathrm{d}}$ \\
\hline $\mathrm{Au}_{3}$ & 2 & $2.695(2.60)^{\mathrm{c}}$ & 1.13 & $1.83(2.70)^{\mathrm{e}}$ \\
\hline $\mathrm{Au}_{4}$ & 1 & $2.710(2.68)^{\mathrm{a}}$ & 1.48 & $0.97(0.927)^{\mathrm{a}}$ \\
\hline $\mathrm{Au}_{5}$ & 2 & $2.678(2.63)^{\mathrm{c}}$ & 1.62 & $0.96(1.142)^{\mathrm{a}}$ \\
\hline $\mathrm{Au}_{6}$ & 1 & $2.712(2.68)^{\mathrm{a}}$ & 1.85 & $2.10(2.05)^{d}$ \\
\hline $\mathrm{Au}_{7}$ & 2 & $2.722(2.70)^{\mathrm{c}}$ & 1.81 & $1.00(1.077)^{\mathrm{a}}$ \\
\hline $\mathrm{Au}_{8}$ & 1 & $2.695(2.67)^{\mathrm{a}}$ & 1.93 & $1.46(1.420)^{\mathrm{a}}$ \\
\hline $\mathrm{Au}_{9}$ & 2 & $2.739(2.72)^{\mathrm{c}}$ & 1.91 & $0.71(0.97)^{\mathrm{c}}$ \\
\hline $\mathrm{Au}_{10}$ & 1 & $2.742(2.71)^{\mathrm{a}}$ & 1.99 & $1.31(1.172)^{\mathrm{a}}$ \\
\hline
\end{tabular}

\subsection{The Geometries, Energetics, and the Electronic Properties of $\mathrm{Au}_{n} \mathrm{O}_{2}$ Complexes}

\subsubsection{Structural Evolution}

The lowest energy geometries of $\mathrm{Au}_{n} \mathrm{O}_{2}(n=2-10)$ clusters and some isomers that have higher energy are displayed in Figure 1. Compared with isolated $\mathrm{Au}_{n}$ clusters and single $\mathrm{O}_{2}$ molecule, most of the $\mathrm{Au}_{n}$ geometries in their lowest energy $\mathrm{Au}_{n} \mathrm{O}_{2}$ clusters and isomers are slightly distorted, but still maintain a planar structure. This situation is believed to reflect the strong scalar relativistic effect in small $\mathrm{Au}$ clusters mentioned in previous studies [34]. But for $\mathrm{Au}_{7} \mathrm{O}_{2}$ and $\mathrm{Au}_{9} \mathrm{O}_{2}$, the situation is quite different and interesting. From Figure 1, it can be seen that the structures of $\mathrm{Au}_{7}$ and $\mathrm{Au}_{9}$ clusters are greatly changed after $\mathrm{O}_{2}$ is adsorbed on their bridge sites. In all geometries of $\mathrm{Au}_{7} \mathrm{O}_{2}$ complex, two evolutionary structures are obtained for $\mathrm{Au}_{7}$ clusters. The lowest energy structure is a planar hexagon with $D_{6 \mathrm{~h}}$ symmetry. The other geometry could be generated by a structural rearrangement from the former. Another structural evolution is observed in $\mathrm{Au}_{9} \mathrm{O}_{2}$ complex. A "bi-edge-capped-hexagon" $\mathrm{Au}_{9}$ structure is generated with $D_{2 \mathrm{~h}}$ symmetry after $\mathrm{O}_{2}$ is adsorbed on the bridge sites. This structure can 
also coexist with the most stable geometry due to its lower electronic energy. The structural evolution of these two clusters is attractive because studies suggest that this phenomenon could only occur in the temperature range of 400 to $500 \mathrm{~K}$ [39]. It is reported that there exists a direct correlation between stability and geometrical structures of the clusters, and relatively higher symmetry clusters are more stable [40]. This is may be one of the reasons for structural evolution after $\mathrm{O}_{2}$ adsorption.

\subsection{2. $\mathrm{O}_{2}$ Adsorption Energies}

Adsorption energy is an important index to examine the adsorption strength and the interactions between adsorbent and adsorbate. This has been investigated in some previous works for $\mathrm{H}_{2}, \mathrm{NO}, \mathrm{CO}$ and $\mathrm{H}_{2} \mathrm{O}$ adsorption onto small Au clusters [41-43]. It can be seen from Figure 2 that for both end-on and bridge adsorption modes, the adsorption energies of $\mathrm{O}_{2}$ on odd-numbered $\mathrm{Au}_{n}$ clusters are larger than those on adjacent even-numbered ones. Furthermore, for odd-numbered $\mathrm{Au}_{n}$ clusters, the adsorption energies of bridge mode are also larger than those of end-on mode. On the contrary, the adsorption energies of end-on mode are larger than those of bridge mode for even-numbered ones, as shown in Figure 2. That is, the odd-numbered $\mathrm{Au}_{n}$ clusters are favoring bridge adsorption of $\mathrm{O}_{2}$ whereas even-numbered ones are favoring end-on adsorption mode. It should be noticed that for $\mathrm{Au}_{2}$, $\mathrm{Au}_{6}$ and $\mathrm{Au}_{8}$ clusters, the $\mathrm{O}_{2}$ molecule could not adsorb on their bridge sites due to the adsorption energy is close to zero. Similarly, the $\mathrm{O}_{2}$ molecule could also not adsorb on the surfaces of the planar $\mathrm{Au}_{6}, \mathrm{Au}_{8}$ and $\mathrm{Au}_{10}$ clusters. The odd-even oscillation of adsorption energies for $\mathrm{Au}_{n} \mathrm{O}_{2}$ clusters is clear evidence based on the analysis above.

Figure 2. Variation of adsorption energy of molecular oxygen with cluster size.

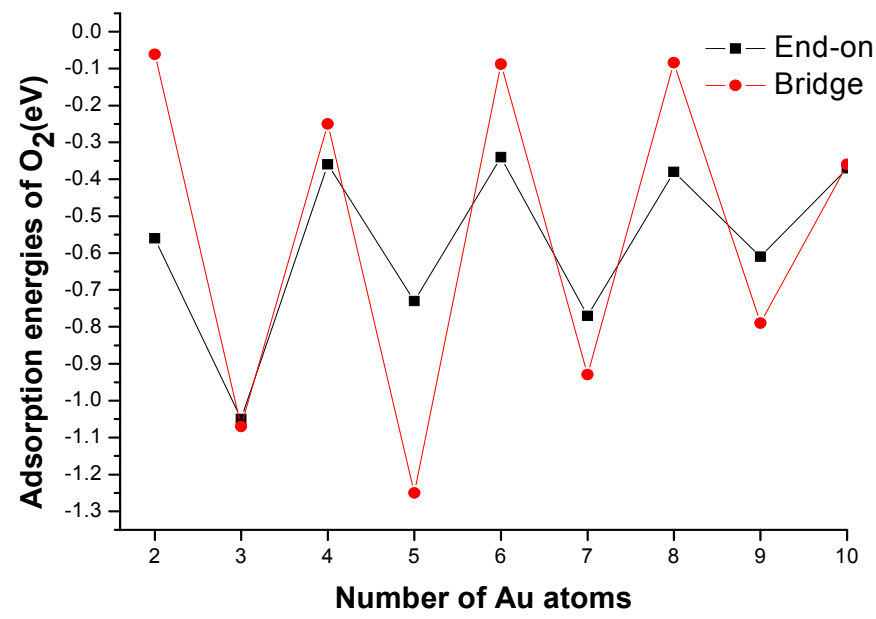

\subsubsection{Activation of $\mathrm{O}_{2}$ Molecules}

The catalytic mechanism of oxygen reduction is to facilitate the dissociation of the $\mathrm{O}-\mathrm{O}$ bond. Therefore, the catalyst's ability to weaken the strong $\mathrm{O}-\mathrm{O}$ bond and the degree of this weakening are crucial for its catalytic activity towards oxygen reduction. From Figure 3, it can be seen that all the studied $\mathrm{Au}_{n}$ clusters have catalytic activity of varying degrees towards $\mathrm{O}_{2}$. The best catalytic activity is observed in $\mathrm{Au}_{5}$ cluster, which causes an $\sim 11 \% \mathrm{O}-\mathrm{O}$ bond elongation. On the contrary, the $\mathrm{Au}_{2}$ cluster has the worst catalytic activity due to its largest HOMO-LUMO energy gap of $2.01 \mathrm{eV}$ (see Table 1). Similar to the variation trends of adsorption energies, for both end-on and bridge adsorption modes, the 
catalytic activity of odd-numbered $\mathrm{Au}_{n}$ clusters are larger than that of adjacent even-numbered ones. For odd-numbered $\mathrm{Au}_{n}$ clusters, the bridge adsorption makes a larger degree of $\mathrm{O}-\mathrm{O}$ bond elongation than that of end-on mode. On the contrary, a larger degree of $\mathrm{O}-\mathrm{O}$ bond elongation of end-on mode is observed in the adjacent even-numbered $\mathrm{Au}_{n}$ clusters.

Figure 3. Variation of elongation ratio of $\mathrm{R}_{\mathrm{O}-\mathrm{O}}$ with cluster size.

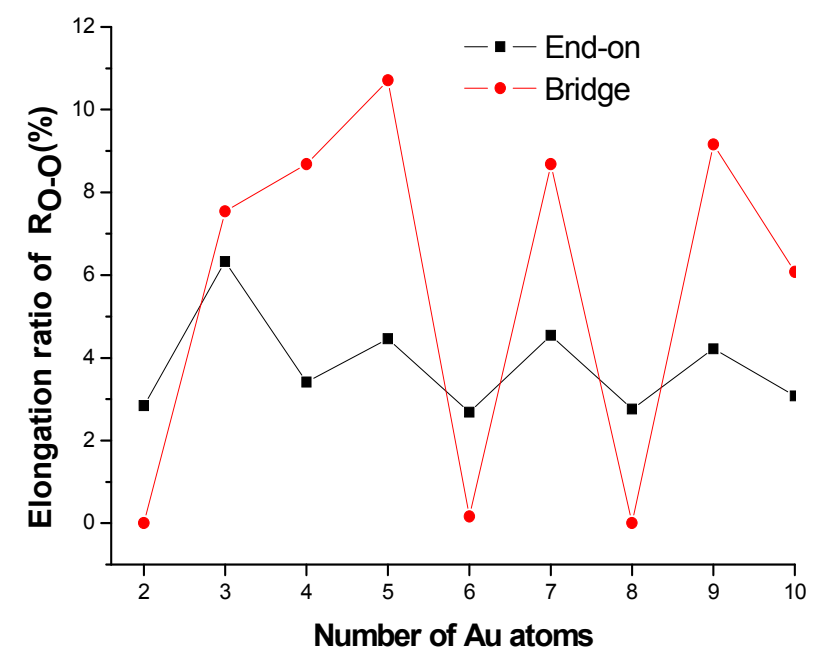

\subsection{The Geometries, Energetics, and the Electronic Properties of $\mathrm{AunO}_{2} / \mathrm{N}-$-Graphene}

\subsubsection{Pure $\mathrm{Au}_{n}$ Clusters on N-Graphene}

In order to analyze the interactions of oxygen with $\mathrm{Au}_{n}$ clusters on $\mathrm{N}$-graphene, the adsorption properties of pure $\mathrm{Au}_{n}(n=2-7)$ clusters supported on N-graphene were firstly considered. Both the perpendicular $(\perp)$ and the parallel ( $\|$ ) orientations of the molecular axis are studied and the results are shown in Table 2. The adsorption energies $\left(E_{3}\right)$ obtained with Equation (3) indicate that the perpendicular orientation is preferred than the parallel one for $\mathrm{Au}_{2}, \mathrm{Au}_{3}$ and $\mathrm{Au}_{4}$ clusters. However, for $\mathrm{Au}_{5}, \mathrm{Au}_{6}$ and $\mathrm{Au}_{7}$ clusters, the most stable orientation is parallel due to their larger adsorption energies. The largest adsorption energy for the studied system is observed in $\mathrm{Au}_{7}$ cluster, which value is $-1.15 \mathrm{eV}$. The total MDC-q charges on the most stable gold adsorption orientation are negative in all cases, suggesting the electron transfer from the support to the metal. However, for their relatively unstable adsorption isomers, the orientation of the electron transfer is reversed. Based on the data that are presented in Table 2, the adsorption strength is mainly due to the electrostatic interactions between the clusters and support. If the $\mathrm{Au}_{n}$ clusters bear more charges (whether positive or negative), the adsorption strength is stronger, otherwise the adsorption strength is relatively weak.

Table 2. Adsorption properties of the studied $\mathrm{Au}_{n}(n=2-7)$ clusters on N-graphene.

\begin{tabular}{cccc}
\hline $\mathrm{Au}_{\boldsymbol{n}}$ cluster & Spin multiplicity & $\boldsymbol{E}_{\mathbf{3}}(\mathbf{e V})$ & MDC-q charge \\
\hline $\mathrm{Au}_{2}, \perp$ & 2 & -0.58 & -0.103 \\
$\mathrm{Au}_{2}, \|$ & 2 & -0.30 & 0.058 \\
$\mathrm{Au}_{3}, \perp$ & 1 & -0.51 & -0.107 \\
$\mathrm{Au}_{3}, \|$ & 1 & -0.30 & 0.030 \\
$\mathrm{Au}_{4}, \perp$ & 2 & -0.81 & -0.089 \\
$\mathrm{Au}_{4}, \|$ & 2 & -0.57 & 0.080 \\
\hline
\end{tabular}


Table 2. Cont.

\begin{tabular}{cccc}
\hline $\mathrm{Au}_{\boldsymbol{n}}$ cluster & Spin multiplicity & $\boldsymbol{E}_{\mathbf{3}}(\mathbf{e V})$ & MDC-q charge \\
\hline $\mathrm{Au}_{5}, \perp$ & 1 & -0.67 & 0.002 \\
$\mathrm{Au}_{5}, \|$ & 1 & -0.79 & -0.019 \\
$\mathrm{Au}_{6}, \perp$ & 2 & -0.64 & 0.098 \\
$\mathrm{Au}_{6}, \|$ & 2 & -0.74 & -0.164 \\
$\mathrm{Au}_{7}, \perp$ & 1 & -0.42 & 0.023 \\
$\mathrm{Au}_{7}, \|$ & 1 & -1.15 & -0.171 \\
\hline
\end{tabular}

\subsection{2. $\mathrm{O}_{2}$ on N-Graphene Supported $\mathrm{Au}_{n}$ Clusters}

Among all the $\mathrm{O}_{2}$ adsorption geometries on isolated $\mathrm{Au}_{n}$ clusters shown in Figure 1, we choose the most stable adsorption modes of "end-on" and "bridge" for each $\mathrm{Au}_{n}(n=2-7)$ cluster and then put these structures on to N-graphene's surface. The calculated results are shown in Table 3. In all cases, the adsorption energies of $\mathrm{O}_{2}$ molecule on $\mathrm{N}$-graphene supported $\mathrm{Au}_{n}$ clusters $\left(E_{2}\right)$ are higher than those on isolated ones $\left(E_{1}\right)$ to varying degrees. There is no doubt that the increased adsorption energies would enhance the catalytic activity of small $\mathrm{Au}_{n}$ clusters. For example, the $\mathrm{O}-\mathrm{O}$ bond lengths on $\mathrm{Au}_{3}$ and $\mathrm{Au}_{4}$ clusters with $\mathrm{N}$-graphene support is largely elongated for both end-on and bridge modes, and are longer than those on isolated ones without support. The optimized structures are shown in Figure 4. It can be seen that the $\mathrm{Au}-\mathrm{O}$ bond distances in the presence of support are further shortened. At the same time, the average $\mathrm{Au}-\mathrm{Au}$ bond lengths have been elongated, as shown in Figure 4. These structural changes significantly facilitate the electron transfer from Au d-orbital to $\pi^{*}$ orbital of $\mathrm{O}_{2}$, which could lead to a charge increasing on $\mathrm{O}_{2}$. From Table 3, it can be seen that there are more negative charges of $\mathrm{O}_{2}$ on $\mathrm{N}$-graphene supported $\mathrm{Au}$ clusters than those on isolated ones. The calculated data indicate that the catalytic activity for oxygen reduction of $\mathrm{Au}_{n}$ clusters could be improved by supporting them on $\mathrm{N}$-graphene through increasing the interaction between the adsorbate and adsorbent. Actually, N-graphene itself has a good oxygen reduction activity both in acid and base solution $[44,45]$. Therefore, when Au clusters are supported on graphene, there may be a synergistic effect between them. This is also an important study area and needs further research.

Table 3. Calculated adsorption energies, $E_{1}$ and $E_{2}(\mathrm{eV})$, and net MDC-q charges, $\Delta \mathrm{Q}$, for $\mathrm{O}_{2}$ molecule in the most stable "end-on" and "bridge" adsorption with and without $\mathrm{N}$-graphene support.

\begin{tabular}{|c|c|c|c|c|c|c|c|c|}
\hline \multirow{2}{*}{$\mathrm{Au}_{n}$ cluster } & \multicolumn{2}{|c|}{$E_{1}(\mathrm{eV})$} & \multicolumn{2}{|c|}{$E_{2}(\mathrm{eV})$} & \multicolumn{2}{|c|}{$\Delta \mathrm{Q}\left(\mathrm{O}_{2}\right)$} & \multicolumn{2}{|c|}{$\Delta Q\left(O_{2}\right.$, with support $)$} \\
\hline & End-on & Bridge & End-on & Bridge & End-on & Bridge & End-on & Bridge \\
\hline $\mathrm{Au}_{2}$ & -0.56 & - & -0.83 & - & 0.041 & - & -0.096 & - \\
\hline $\mathrm{Au}_{3}$ & -1.05 & -1.07 & -1.26 & -1.69 & -0.161 & -0.191 & -0.261 & -0.272 \\
\hline $\mathrm{Au}_{4}$ & -0.36 & -0.25 & -0.42 & -0.30 & -0.077 & -0.073 & -0.157 & -0.091 \\
\hline $\mathrm{Au}_{5}$ & -0.73 & -1.25 & -0.77 & -1.32 & -0.084 & -0.203 & -0.259 & -0.223 \\
\hline $\mathrm{Au}_{6}$ & -0.34 & - & -0.52 & - & -0.126 & - & -0.134 & - \\
\hline $\mathrm{Au}_{7}$ & -0.77 & -0.93 & -0.86 & -0.99 & -0.169 & -0.231 & -0.198 & -0.248 \\
\hline
\end{tabular}


Figure 4. Key bond lengths for the optimized structures of the $\mathrm{O}_{2}$ molecule adsorbed on $\mathrm{N}$-graphene supported $\mathrm{Au}_{3}$ and $\mathrm{Au}_{4}$ cluster, respectively (distances are in angstrom).
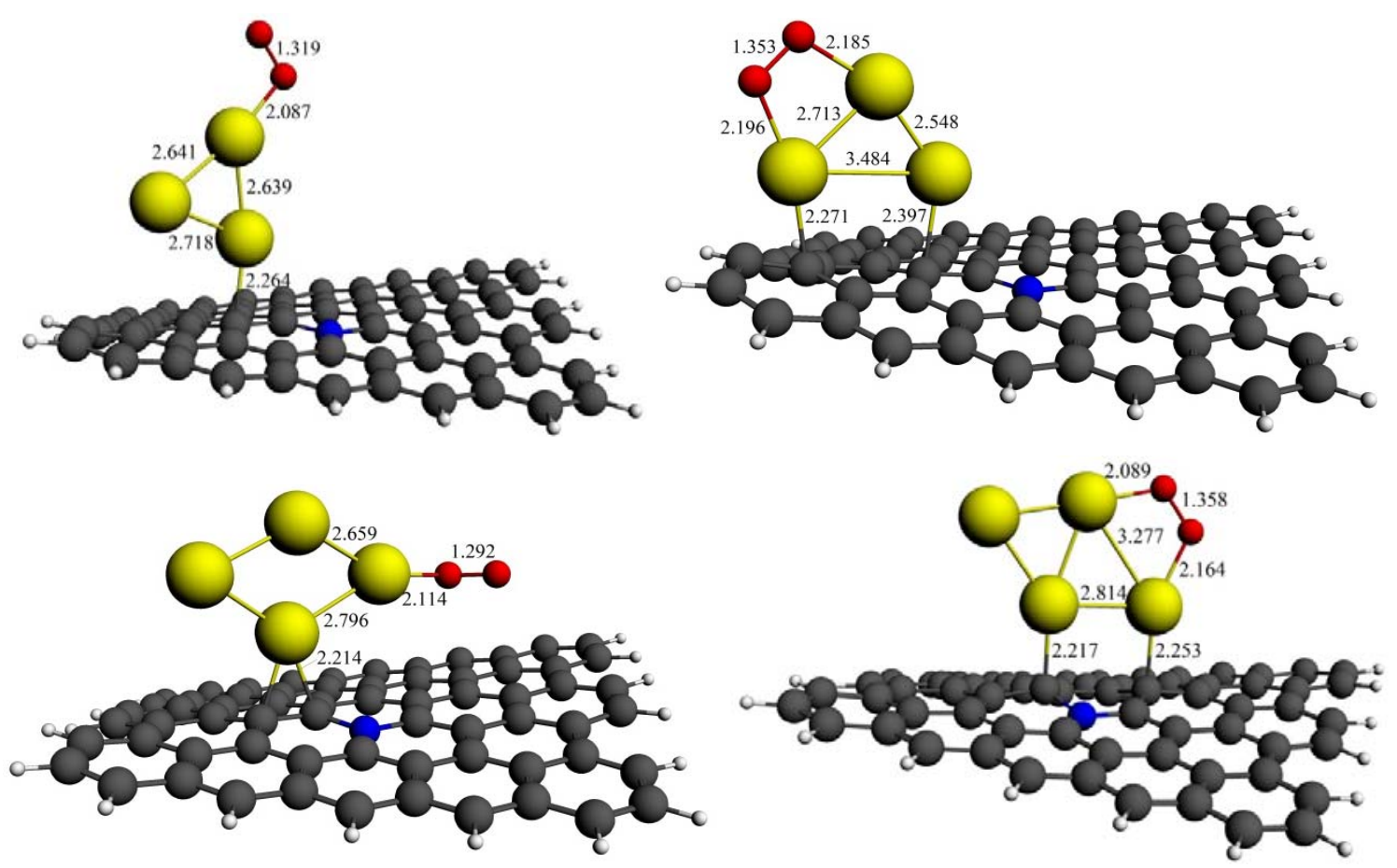

To further clarify the enhanced catalytic activity, the adsorption energies of two important species involved in oxygen reduction, $\mathrm{O}$ and $\mathrm{OH}$, are also calculated, as shown in Table 4. Being similar to the adsorption properties of $\mathrm{O}_{2}$ molecule, the adsorption energies of atomic $\mathrm{O}$ on $\mathrm{N}$-graphene supported $\mathrm{Au}_{n}$ clusters $\left(E_{2}\right)$ are all higher than those on isolated ones $\left(E_{1}\right)$. It is reported that the stronger a material binds atomic $\mathrm{O}$, the more effective it will be in breaking apart molecular $\mathrm{O}_{2}$, which could be used to identify the efficiency of a catalyst [46-48], and therefore the enhanced catalytic activity is further confirmed. In addition, experimental results indicate that the strong $\mathrm{OH}$ adsorption on $\mathrm{Pt}$ may induce overpotential [49], which caused by the coverage of adsorbed $\mathrm{OH}$ on Pt surface and then block the adsorption of $\mathrm{O}_{2}$ in the next reduction step. From Table 4, it can be seen that when $\mathrm{OH}$ is adsorbed on $\mathrm{N}$-graphene supported $\mathrm{Au}_{7}$ cluster, the adsorption energies are decreased. Therefore, the adsorbed $\mathrm{Au}$ clusters on $\mathrm{N}$-graphene may also reduce the overpotential of oxygen reduction.

Table 4. Calculated adsorption energies of $\mathrm{O}$ and $\mathrm{OH}$ on $\mathrm{Au}_{n}(n=4,7)$ clusters with and without N-graphene support.

\begin{tabular}{ccccc}
\hline $\mathrm{Au}_{\boldsymbol{n}}$ cluster & $\boldsymbol{E}_{\mathbf{1}}(\mathbf{O})$ & $\boldsymbol{E}_{\mathbf{2}}(\mathbf{O}$, with support $)$ & $\boldsymbol{E}_{\mathbf{1}}(\mathbf{O H})$ & $\boldsymbol{E}_{\mathbf{2}}(\mathbf{O H}$, with support $)$ \\
\hline $\mathrm{Au}_{4}$ & -3.43 & -3.96 & -2.75 & -2.97 \\
$\mathrm{Au}_{7}, \perp$ & & -3.99 & -3.80 & -3.50 \\
$\mathrm{Au}_{7}, \|$ & -4.21 & -4.34 & -3.65 \\
\hline
\end{tabular}

\subsubsection{Improved Structural Stability of $\mathrm{Au}_{n}$ Clusters}

As discussed in Section 3.2.1, the geometrical structures of pure $\mathrm{Au}_{7}$ and $\mathrm{Au}_{9}$ clusters would be greatly changed after $\mathrm{O}_{2}$ is adsorbed on their bridge sites. It is reported that the shape changes could modify the $\mathrm{O}_{2}$ bonding mode, therefore alter the cluster's catalytic activity [50]. Thus, enhancing the 
cluster's stability without decreasing its catalytic activity is an important issue for catalytic applications. Figure 5 shows both the parallel and perpendicular orientations of $\mathrm{Au}_{7}$ cluster supported on $\mathrm{N}$-graphene with $\mathrm{O}_{2}$ adsorption. It is clearly seen that although the cluster geometry of parallel orientation has a little distortion when compared with the isolated structure, the basal cluster morphology is still maintained. The geometry of the cluster for the perpendicular case barely changed even $\mathrm{O}_{2}$ adsorbed on bridge sites. The reason that $\mathrm{N}$-graphene enhanced the stability of $\mathrm{Au}_{n}$ cluster could be attributed to the interactions between the metal atoms and the surface. For perpendicular case, the carbon atoms on N-graphene could anchor the cluster, which make it more difficult to structural distortion. In the case of parallel orientation, although there is no direct $\mathrm{Au}-\mathrm{C}($ or $\mathrm{Au}-\mathrm{N})$ interaction, the morphology of the cluster is also difficult to change due to strong adsorption energy between the cluster and the surface $(-1.15 \mathrm{eV})$, as shown in Table 2 .

Figure 5. Optimized structures of the $\mathrm{O}_{2}$ molecule adsorbed on $\mathrm{N}$-graphene supported $\mathrm{Au}_{7}$ cluster with bridge mode (distances are in angstrom).
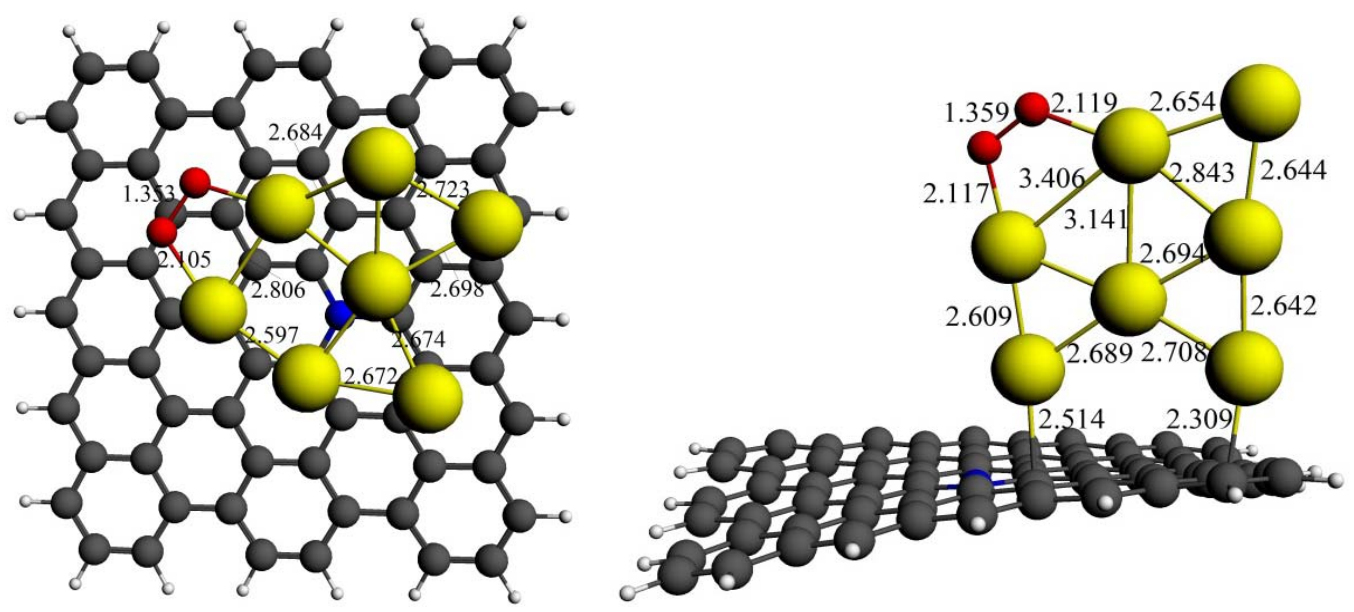

\section{Conclusions}

By means of density functional theory, the adsorption properties of $\mathrm{O}_{2}$ on both isolated and $\mathrm{N}$-graphene supported gold clusters have been studied. Our results indicate that the adsorption energies of $\mathrm{O}_{2}$ on odd-numbered $\mathrm{Au}$ clusters are larger than those on adjacent even-numbered ones. Similarly, the catalytic activity of odd-numbered $\mathrm{Au}_{n}$ clusters, which is measured by the $\mathrm{O}-\mathrm{O}$ bond weakening, is also higher than that of neighboring even-numbered ones. The odd-even oscillation of adsorption energies for $\mathrm{Au}_{n} \mathrm{O}_{2}$ is clearly evident. Furthermore, the $\mathrm{O}_{2}$ molecule is in favor of bonding to the bridge sites of odd-numbered $\mathrm{Au}_{n}$ clusters, whereas for odd-numbered ones, the end-on adsorption mode is favored.

The adsorption energies on $\mathrm{N}$-graphene of all studied clusters are in the range from -0.30 to $-1.15 \mathrm{eV}$. The perpendicular orientation is preferred than the parallel ones for $\mathrm{Au}_{2}, \mathrm{Au}_{3}$ and $\mathrm{Au}_{4}$ clusters, whereas for $\mathrm{Au}_{5}, \mathrm{Au}_{6}$ and $\mathrm{Au}_{7}$, the situation is quite the contrary. Charge analysis suggests that the adsorption strength is mainly due to the electrostatic interactions between the clusters and support.

When $\mathrm{O}_{2}$ is adsorbed on $\mathrm{N}$-graphene supported $\mathrm{Au}_{n}$ clusters, the adsorption energies are largely increased compared with those on isolated ones. The increased adsorption energies could significantly facilitate the electron transfer from $\mathrm{Au}$ d-orbital to $\pi^{*}$ orbital of $\mathrm{O}_{2}$, which could further weaken the $\mathrm{O}-\mathrm{O}$ bond and therefore enhancing the catalytic activity. This is also confirmed by the increased 
adsorption energy of atomic $\mathrm{O}$ on $\mathrm{N}$-graphene supported $\mathrm{Au}_{n}(n=4,7)$ clusters. The carbon atoms on $\mathrm{N}$-graphene could anchor the clusters and make it more difficult to structural distortion, therefore enhance their stability.

\section{Acknowledgments}

This work was performed with the financial supports from the major program of Beijing Municipal Natural Science Foundation (No. 20110001), the National Natural Science Foundation of China (Nos. 11179001, 51172007) and the Doctoral Fund of Innovation of Beijing University of Technology.

\section{References}

1. Wallace, W.T.; Whetten, R.L. Coadsorption of $\mathrm{CO}$ and $\mathrm{O}_{2}$ on selected gold clusters: Evidence for efficient room-temperature $\mathrm{CO}_{2}$ generation. J. Am. Chem. Soc. 2002, 124, 7499-7505.

2. Hagen, J.; Socaciu, L.D.; Elijazyfer, M.; Heiz, U.; Bernhardt, T.M.; Woste, L. Coadsorption of $\mathrm{CO}$ and $\mathrm{O}_{2}$ on small free gold cluster anions at cryogenic temperatures: Model complexes for catalytic CO oxidation. Phys. Chem. Chem. Phys. 2002, 4, 1707-1709.

3. Hakkinen, H.; Landman, U. Gas-phase catalytic oxidation of $\mathrm{CO}$ by $\mathrm{Au}_{2}^{-}$. J. Am. Chem. Soc. 2001, 123, 9704-9705.

4. Lopez, N.; Norskov, J.K. Catalytic CO oxidation by a gold nanoparticle: A density functional study. J. Am. Chem. Soc. 2002, 124, 11262-11263.

5. Molina, L.M.; Hammer, B. Active role of oxide support during $\mathrm{CO}$ oxidation at $\mathrm{Au} / \mathrm{MgO}$. Phys. Rev. Lett. 2003, 90, 206102.

6. Boccuzzi, F.; Chiorino, A. FTIR study of $\mathrm{CO}$ oxidation on $\mathrm{Au} / \mathrm{TiO}_{2}$ at $90 \mathrm{~K}$ and room temperature. An insight into the nature of the reaction centers. J. Phys. Chem. B 2000, 104, 5414-5416.

7. Choudhary, T.V.; Goodman, D.W. Oxidation catalysis by supported gold nano-clusters. Top. Catal. 2002, 21, 25-34.

8. Assadollahzadeh, B.; Schwerdtfeger, P. A systematic search for minimum structures of small gold clusters $\mathrm{Au}_{\mathrm{n}}(\mathrm{n}=2-20)$ and their electronic properties. J. Chem. Phys. 2009, 131, 064306.

9. Kang, G.J.; Chen, Z.X.; Li, Z.; He, X. A theoretical study of the effects of the charge state and size of gold clusters on the adsorption and dissociation of $\mathrm{H}_{2}$. J. Chem. Phys. 2009, 130, 034701.

10. Li, G.P.; Hamilton, I.P. Complexes of small neutral gold clusters and hydrogen sulphide: A theoretical study. Chem. Phys. Lett. 2006, 420, 474-479.

11. Yoon, B.; Hakkinen, H.; Landman, U. Interaction of $\mathrm{O}_{2}$ with gold clusters: Molecular and dissociative adsorption. J. Phys. Chem. A 2003, 107, 4066-4071.

12. Mills, G.; Gordon, M.S.; Metiu, H. The adsorption of molecular oxygen on neutral and negative $\mathrm{Au}_{n}$ clusters $(n=2-5)$. Chem. Phys. Lett. 2002, 359, 493-499.

13. Ding, X.; Li, Z.; Yang, J.; Hou, J.G.; Zhu, Q. Adsorption energies of molecular oxygen on Au clusters. J. Chem. Phys. 2004, 120, 9594-9600.

14. Fernandez, E.M.; Ordejon, P.; Balbas, L.C. Theoretical study of $\mathrm{O}_{2}$ and $\mathrm{CO}$ adsorption on $\mathrm{Au}_{n}$ clusters $(n=5-10)$. Chem. Phys. Lett. 2005, 408, 252-257.

15. Lyalin, A.; Taketsugu, T. Cooperative adsorptionof $\mathrm{O}_{2}$ and $\mathrm{C}_{2} \mathrm{H}_{4}$ on small gold clusters. J. Phys. Chem. C 2009, 113, 12930-12934. 
16. Coquet, R.; Howard, K.L.; Willock, D.J. Theory and simulation in heterogeneous gold catalysis. Chem. Soc. Rev. 2008, 37, 2046-2076.

17. Novoselov, K.S.; Geim, A.K.; Morozov, S.V.; Jiang, D.; Katsnelson, M.I.; Grigorieva, I.V.; Dubonos, S.V.; Firsov, A.A. Two-dimensional gas of massless dirac fermions in graphene. Nature 2005, 438, 197-200.

18. Zhang, Y.B.; Tan, Y.W.; Stormer, H.L.; Kim, P. Experimental observation of the quantum Hall effect and Berry's phase in graphene. Nature 2005, 438, 201-204.

19. Novoselov, K.S.; McCann, E.; Morozov, S.V.; Fal'ko, V.I.; Katsnelson, M.I.; Zeitler, U.; Jiang, D.; Schedin, F.; Geim, A.K. Unconventional quantum Hall effect and Berry's phase of $2_{\pi}$ in bilayer graphene. Nat. Phys. 2006, 2, 177-180.

20. Castro Neto, A.H.; Guinea, F.; Peres, N.M.R.; Novoselov, K.S.; Geim, A.K. The electronic properties of graphene. Rev. Mod. Phys. 2009, 81, 109-162.

21. Yoo, E.; Okata, T.; Akita, T.; Kohyama, M.; Nakamura, J.; Honma, I. Enhanced electrocatalytic activity of Pt subnanoclusters on graphene nanosheet surface. Nano Lett. 2009, 9, 2255-2259.

22. Scheuermann, G.M.; Rumi, L.; Steurer, P.; Bannwarth, W.; Mulhaupt, R. Palladium nanoparticles on graphite oxide and its functionalized graphene derivatives as highly active catalysts for the Suzuki-Miyaura coupling reaction. J. Am. Chem. Soc. 2009, 131, 8262-8270.

23. Pulido, A.; Boronat, M.; Corma, A. Theoretical investigation of gold clusters supported on graphene sheets. New J. Chem. 2011, 35, 2153-2161.

24. Chen, G.; Li, S.J.; Su, Y.; Wang, V.; Mizuseki, H.; Kawazoe, Y. Improved stability and catalytic properties of $\mathrm{Au}_{16}$ cluster supported on graphane. J. Phys. Chem. C 2011, 115, 20168-20174.

25. te Velde, G.; Bickelhaupt, F.M.; Baerends, E.J.; Fonseca Guerra, C.; van Gisbergen, S.J.A.; Snijders, J.G.; Ziegler, T. Chemistry with ADF. J. Comput. Chem. 2001, 22, 931-967.

26. Fonseca Guerra, C.; Snijders, J.G.; te Velde, G.; Baerends, E.J. Towards an order-N DFT method. Theor. Chem. Acc. 1998, 99, 391-403.

27. ADF2009.01, SCM, Theoretical Chemistry, Vrije Universiteit, Amsterdam, The Netherlands. SCM Home Page. http://www.scm.com (accessed on 5 March 2013).

28. Swart, M.; van Duijnen, P.T.; Snijders, J.G. A charge analysis derived from an atomic multipole expansion. J. Comput. Chem. 2001, 22, 79-88.

29. Häkkinen, H.; Moseler, M.; Landman, U. Bonding in $\mathrm{Cu}, \mathrm{Ag}$, and Au clusters: Relativistic effects, trends, and surprises. Phys. Rev. Lett. 2002, 89, 033401.

30. Häkkinen, H.; Yoon, B.; Landman, U.; Li, X.; Zhai, H.J.; Wang, L.S. On the electronic and atomic structures of small AuN- $(\mathrm{N}=4-14)$ clusters: A photoelectron spectroscopy and density-functional study. J. Phys. Chem. A 2003, 107, 6168-6175.

31. Deka, A.; Deka, R.C. Structural and electronic properties of stable $\mathrm{Au}_{n}(n=2-13)$ clusters: A density functional study. J. Mol. Struc.-Theochem. 2008, 870, 83-93.

32. Hakkinen, H.; Landman, U. Gold clusters $\left(\mathrm{Au}_{N}, 2<=N<=10\right)$ and their anions. Phys. Rev. B 2000, 62, R2287-R2290.

33. Lee, H.M.; Ge, M.; Sahu, B.R.; Tarakeswar, P.; Kim, K.S. Geometrical and electronic structures of gold, silver, and gold-silver binary clusters: Origins of ductility of gold and gold-silver alloy formation. J. Phys. Chem. B 2003, 107, 9994-10005. 
34. Fernandez, E.M.; Soler, J.M.; Garzon, I.L.; Balbas, L.C. Trends in the structure and bonding of noble metal clusters. Phys. Rev. B 2004, 70, 165403.

35. Kuang, X.J.; Wang, X.Q.; Liu, G.B. All-electron scalar relativistic calculation of water molecule adsorption onto small gold clusters. J. Mol. Model. 2011, 17, 2005-2016.

36. Bishea, G.A.; Morse, M.D. Spectroscopic studies of jetcooled AgAu and $\mathrm{Au}_{2}$. J. Chem. Phys. 1991, 95, 5646-5659.

37. Shafai, G.S.; Shetty, S.; Krishnamurty, S.; Shah, V.; Kanhere, D.G. Density functional investigation of the interaction of acetone with small gold clusters. J. Chem. Phys. 2007, 126, 014704.

38. Wang, J.; Wang, G.; Zhao, J. Density-functional study of $\mathrm{Au}_{n}(n=2-20)$ clusters: Lowest-energy structures and electronic properties. Phys. Rev. B 2002, 66, 035418.

39. De, H.S.; Krishnamurty, S.; Mishra, D.; Pal, S. Finite temperature behavior of gas phase neutral $\mathrm{Au}_{n}(3 \leq \mathrm{n} \leq 10)$ clusters: A first principles investigation. J. Phys. Chem. C 2011, 115, 17278-17285.

40. Zhou, J.C.; Li, W.J.; Zhu, J.B. Particle swarm optimization computer simulation of Ni clusters. Trans. Nonferrous. Met. Soc. China 2008, 18, 410-415.

41. Ding, X.L.; Li, Z.Y.; Yang, J.L.; Hou, J.G.; Zhu, Q.S. Theoretical study of nitric oxide adsorption on Au clusters. J. Chem. Phys. 2004, 121, 2558-2562.

42. Wu, X.; Senapati, L.; Nayak, S.K.; Selloni, A.; Hajaligol, M. A density functional study of carbon monoxide adsorption on small cationic, neutral, and anionic gold clusters. J. Chem. Phys. 2002, $117,4010-4015$.

43. Ghebriel, H.W.; Kshirsagar, A. Adsorption of molecular hydrogen and hydrogen sulfide on Au clusters. J. Chem. Phys. 2007, 126, 244705.

44. Zhang, L.; Xia, Z. Mechanisms of oxygen reduction reaction on nitrogen-doped graphene for fuel cells. J. Phys. Chem. C 2011, 115, 11170-11176.

45. Yu, L.; Pan, X.; Cao, X.; Hu, P.; Bao, X. Oxygen reduction reaction mechanism on nitrogen-doped graphene: A density functional theory study. J. Catal. 2011, 282, 183-190.

46. Xu, Y.; Ruban, A.V.; Mavrikakis, M. Adsorption and dissociation of $\mathrm{O}_{2}$ on Pt-Co and Pt-Fe alloys. J. Am. Chem. Soc. 2004, 126, 4717-4725.

47. Chen, X.; Li, F.; Wang, X.; Sun, S.; Xia, D. Density functional theory study of the oxygen reduction reaction on a cobalt-polypyrrole composite catalyst. J. Phys. Chem. C 2012, 116, 12553-12558.

48. Chen, X.; Sun, S.; Wang, X.; Li, F.; Xia, D. DFT study of polyaniline and metal composites as nonprecious metal catalysts for oxygen reduction in fuel cells. J. Phys. Chem. C 2012, 116, $22737-22742$.

49. Uribe, F.A.; Zawodzinski, T.A., Jr. A study of polymer electrolyte fuel cell performance at high voltages. Dependence on cathode catalyst layer composition and on voltage conditioning. Electrochim. Acta 2002, 47, 3799-3806.

50. Lamas, E.J.; Balbuena, P.B. Adsorbate effects on structure and shape of supported nanoclusters: A molecular dynamics study. J. Phys. Chem. B 2003, 107, 11682-11689.

Sample Availability: Not Available.

(C) 2013 by the authors; licensee MDPI, Basel, Switzerland. This article is an open access article distributed under the terms and conditions of the Creative Commons Attribution license (http://creativecommons.org/licenses/by/3.0/). 